How the two orders of remedies seem conjointly to analyse the nature of the diseases with which they have to do!

There is a good deal of difference how we regard the effects of the same special remedy, according as it is brought to bear upon an acute or a chronic disease, and as its own operation is rapid or slow. The nearness or remoteness of the result strengthens or weakens our faith in the power of the remedy. If some sure earnest of the coming result follow the first use of the remedy, and the result, even the cure, be complete within a few days, then we have all that reason can ask for faith in the special remedy from first to last. But if the result be postponed for weeks, and still postponed for months, and the earnests in the meanwhile, upon which hope likes to lean and to refresh itself, be few and long betweenthen, though the result arrive at last, even the perfect cure, the reason gives but a hesitating faith to the special remedy for its share in procuring it.

So when quinine is prescribed for an ague, or for any rapidly progressive disease to which fever belongs, such as erysipelas or acute rheumatism, and it ceases abruptly or soon, or in a few days, our faith in the remedy as of special efficacy is complete. But when quinine is given for strumous ophthalmia, or for swelled absorbent glands of the neck, or for any complaint of whatever name which has the accompaniment of a weak and cachectic constitution, and the ophthalmia or the swelled glands disappear and health follows after the lapse of months, then our faith in the special remedy, as such, gets a good deal frittered away or is exchanged for the more moderate expectation of good which waits upon the use of tonic medicines. It sinks from a specific to a tonic, which is a great fall. In like manner colchicum, given for the paroxysm of gout, and at once abating its severity and finally abolishing it in a few days, is justly regarded and trusted as a special remedy; but given and continued week after week for chronic pains of doubtful pathology, and those pains in the meantime slowly and reluctantly yielding, and at length giving in altogether, we thus lose faith in colchicum as a specific for gout. If we allow it any credit in the result, it is of another kind. It sinks from a specific to an alterative, which is a great fall.

But let us beware of all debate about "tonic" and "alterative"; which, whether applied to remedies or to their operation, are most without meaning of all the terms in use among physicians. Tonics and alteratives include a countless heap of things, and get much of the credit they have as a class from a few remedies, passing by their names, which better deserve to be called special or specific; as cinchona when it cures other diseases besides ague, and sarsaparilla when it cures chronic syphilis. As to quassia, and gentian, and cascarilla, and cusparia, and orangepeel, they should rather be reckoned as condiments for food than as medicines.

This may seem a hard sentence to pass upon timehonoured remedies, and so to dissever them from the art altogether. Within the memory of man, bitters were in high esteem, and their virtues were nicely studied. There were those who could tell you which was to be preferred to which, and were not to be caught confounding their effects, and giving one when they ought to give another. The abundance of drugs to be taken was a chief characteristic of medicine as it was practised forty years ago, and not unnaturally it did its best to believe or make-believe in their efficacy.

Here we take leave of Cures and Special Remedies as a formal part of our subject; but they will still be meeting us at every turn. In truth, what we have called special and common remedies never so well display their powers as when they are seen at work concurrently or in conflict with each other. Remedies, indeed, are our great analysers of disease; common remedies more plainly and sensibly, special remedies more intimately and profoundly, but both alike in fact. Of living disease hardly any analysis is possible but by help of both.

\section{(1) bserbations}

\section{TYPHOID OR IN'TESTINAL FEVER: THE PYTHOGENIC THEORY.}

$\mathrm{BY}$

WILLIAM BUDD, M.D.,

SENIOR PHYSICIAN TO THE BRISTOL ROYAL INFIEMARY.

"So the ordinary face and view of experience is many times satisfled by several theories and philosophies; whereas, to find the real truth, requireth another mauner of severity and attention." (Advancement of Learning.)

\section{PART II.}

Intmusion of Sentiment into the Domain of Science. Miss Nightingale's Views. The Idea that the Specific Poison of Fever is generated by the Processes of Common Putrescence, irreconcileable with the intensely Specific Conditions which attach to its Reproduction in the Living Body. The enormous rate of this Reproduction adequate to all the Phenomena.

Some years ago I was taken severely to task by one of the first literary men of the day for contending that cholera is contagious. After observing that the idea had been discarded by all the great authorities, including the Royal College of Physicians and the General Board of Health, who, after an elaborate investigation conducted by men of the highest scientific eminence, had lately reported on the subject, he added that he wondered I was not ashamed to teach such an "immoral" doctrine. And, following up the taunt, he proceeded with great fervour to depict the social horrors that would ensue were such a doctrine generally adopted. Although it was evident that my opponent carried the sympathies of the audience with him, the slightest reflection would have shown that his attack was not only unjust, but absurd. For, clearly erough, this is not a question of morality or immorality at all, but simply a question of evidence, to be judged by the laws by which all evidence must be judged.

Strange as it was to hear such language from a great popular teacher, it was still more strange to meet with it in a medical work. Whatever may be the case with men in other callings, physicians are supposed to know something, at least, of the principles on which all science must be based.

$\mathrm{Be}$ this as it may, in the official report of the New Orleans Commission appointed to inquire into the origin of the great epidemic of yellow fever which ravaged that city in the summer of 1853 , the same 
argument occurs. After stating that yellow fever depends on an "infection" in the generation of which only two factors-great moisture and a very high temperature - are needed, the official reporter, Dr. E. H. Barton, adds: "It will be thus seen how truthfully and how philosophically this explanation comes in to substitute itself for that most unsatisfactory and barbarous one of contagion; sundering, so far as it extends its creed, every tie that binds man to man, as we have unfortunately found to be the case in many instances during the last season in the interior-not in the city, where the doctrine is entirely new." "The inhumanity of that attribution is only equalled by its folly." And, running on for a whole column in a similar strain, the author-to clench his argument with a glowing contrast-dis. misses the topic with this triumphant peroration: "Infection is not a personal quality; it applies to vitiated air, from whatever cause proceeding. It is the product, not the producer. It is the REM! (sic)."

The logic, as we have seen, is not singular; but there is in Dr. Barton's whole manner of dealing with the subject, and in the climax especially, a certain transatlantic smack which gives an additional gusto to it.

In England, the sentiment appears to be taking a somewhat different turn. In a leader which appeared in the Medical Times and Gazette for the 9th February last, under the heading "Abandonment of the Doctrine of the Specificity of Contagious Diseases", the writer states that, one by one, authors and observers are declaring their belief that these diseases "may originate de novo out of the dirt and neglect which surround us." After citing the opinions of Dr. Murchison, Dr. Druitt, Mr. Simon, and Dr. Milroy, in proof of his assertion, he adds that the paper lately read to the Epidemiological Society by the last named gentleman* applies the same idea still more widely, and "shows a tendency in the professional mind to adopt new and what may be called more liberal views". $†$

* On the Influence of Contagion in the Diffusion of Epidemic Disorders.

+ 'The following is the article entire:-"We find that, one by one, writers and observers appear to abandon the doctrine of the 'speci. ficity' of contagious diserses, and to declare their belief that they may arise from time to time de novo, out of the dirt and neglect which surround us. We give in another column, an extract from Percival's Lectures, which shows wlint his belief was, as to the origin of glanders in the horse, more than thirty years ago. Sunitury reformers have long shown the origin of diarrhœa in fæecal effluvia. Dr. Murchison lias traced typhoid to the same cause; and in a lecture lelivered before the Roval Institution in 1859 , nnd ancther before the Royal Institute of British Architects in 1860, Dr. Druitt summed up the evidence in favour of the spontaneous origin of scarlatina, diphtherin, erysipelas, hespital gangrene, drsentery, and ophthalinia, and of their propagation by contagion under favourable ophthalinia, and of their propagation by contagion under favourable
circumstances. Mr. Simon has conceded the spontaneous origin of gonolrhœa and ophthalmin, and the contagiousness of suppuration as a rule. 1)r. Milroy, in a recent paper read before the Epidemio. logical Society, gues over most of the same ground. He referred to the spontaneous origin of hydrophobia, and of purulent ophthalmia, and to the undoubted fact of the occasional propagation of the latter by at mosplieric dispersion. He showed the close aftinity between the plarue and typhus fever, in origin, development, and obedience to hygituic mensures; and the belief that the plague may arise ac noro, is confirmed by the fact of its appearance on the Bombay coast recently. With regard to the yellow fever, Dr. Milroy shows that in upwarls of one thousand cases in the Quarantine fospital it New York, the disease never spread by contagion, though the case was otherwise on board the Eclair. So also cholera, he believes, may be cenerated de novo, and likewise propagated by contagion, if the circumstauces be favourable; the same with dysentery, erysipelas, and puerperal fever. On these subjects, Dr. Milroy seems to agree with the views of the authors we have mentioned; and his proper shows a tendency in the professional mind to adopt new and what we may eail liberal views."

I need scarcely add that, in giving this extract. I have no intention of making these gentlemen responsible for this account of their opinious.
In the country of Locke and Bacon, the criterion by which scientific view's are judged would be, one would suppose, their truth or otherwise; but, according to this writer, who represents, by the way, no inconsiderable school, the question now would seem to be, not whether such views be true, but whether they be "liberal".

Under the inspiration of the same sentiment, Miss Nightingale has added one more to the list of alleged discoveries enumerated by the editor of the Medical Times and Gazette. In one of the notes appended to her little book on Nursing, this truly eminent lady asserts that "she has seen with her eyes and smelt with her nose" the small-pox in the very act of formation in close rooms and overcrowded hospital wards. * This is probably the most remarkable instance yet made public of the power of that "deductive faculty" which Mr. Buckle looks upon as so supreme in woman, and which, according to that philosopher, is destined to wrest from Nature so many and such great truths, "to the glory of God and the relief of man's estate".

It may be an unworthy prejudice, but those who have most considered the subject will probably agree with me in preferring, as far as small-pox is concerned, the more tedious but safer path of the inductive method.

All the vague and untenable notions which have of late years gathered round this subject, more particularly in relation to the propagation of intestinal fever and some other epidemic disorders, may be traced either to ignorance of their contagious properties, or to want c funsight into what contagion involves. "If once a disease of this kind", says Dr. Watson, in his pleasant and masterly discussion of this subject, " is decidedly proved to be the effect of contagion, we cannot help entertaining a doubt whether the disorder in question really ever has any other cause." The more we reflect on this observation, the more just it will appear. In a former paper (Lancet, July 23, 1859) I have already shown that, in intestinal fever, dissemination by contagion implies

* The following is the entire passage :- "Is it not living in a con tinual mistake to look upon diseases, as we do now, as separate entities, which must exist, like cats and dogs? instead of looking upon them as conditions, like a dirty and a clean condition, and just as much under our own control; or rather, as the reactions of kindly nature, against the conditions in which we have placed ourselves.

"I was brought up both by scientific men and ignorant women distinctly to believe that small-pox, for instance, was a thing of which there was once a first specimen in the world, which went on propagating itself in a perpetual chain of descent, just as much as that there was a first dog (or first pair of dogs), and that small-nox would not begin itself any more than a new dog would begin with. out there having been a parent dog.

- Since then, I have seen with my eyes and smelt with my nose small-pox growing up in first specimeus, either in close rooms, or in overcrowded wards, where it could not by any possibility have been caught, but must have begun. Nay, more, I have seen diseases begin, grow up, and pass into one another. Now, dogs do not pass inte cats. I have seen, for instance, with a little overerowding coutinued fever grow up; and with a little more, typhoid fever. and with o little more, typhus; and all in the same ward or hut Would it not be far better, truer, and more practical, if we looked upon disease in this light? For diseases, as all experience shows, are adjectives, not noun substantives."

It is much to be regretted that this lady, whose name is so justly dear to the nation, should distigure her admirable notes on nursing by crude and dogmatic assertions or questious, which lie beyond her province. Great as Miss Nightingale's abilities and powers of observation are, it is no reproach to her that she is not yualitied to solve the highest problems of medical scieuce. Her authority on her own subject is deservelly so high, that it becomes the more necessary to put readers on their guard against her opinions, whoro they are erroneous. I have seen so many valuable lives sacrificed to the senseless dogma that fever is not contagious, that I have felt it a solemn duty to make this protest against this reproduction of it in a book that is in every one's hands. 
precisely what it implies in small-pox; and that it is provided for in the same way by the multiplication of a specific poison in the most intimate recesses of the living body, by that most remarkable of processes which constitutes the phenomena of a contagious fever.

Even on the most superficial view, it is difficult to suppose that an agent which is evolved by such a process as this can be the offspring of any other. Still more difficult is it to suppose that an agent so evolved can be the product of merely external conditions. To see in all its force how intensely specific a thing the propagation of these poisons in the human body is, we must bear in mind that they are not one, but many. Multiplying in the same remarkable medium-bred, therefore, of the same materials, and still more by the same peculiar lawyet each of these several poisons sets up a series of changes which always issues in the reproduction of its own specific kind-small-pox in small-pox, scarlet fever in scarlet fever, and so on. What smallpox and measles were in the Arab in the days of Rhazes, they still are in the London Cockney in our own. What they are in the London Cockney, they are in the wild Indian of the North American prairie, and in the Negro of the Gold Coast. To all the other contagious fevers, as far as our records go, the same remark applies. In races the most diverse, under climates the most various, age after age, through endless generations of men, these diseases pass down through the human body, perpetuating their own kind, and each maintaining its separate identity by marks as specific as those which distinguish the asp from the adder, or the hemlock from the poppy. To say the least, it is difficult to conceive that agents of whose propagation this is the history can be generated in any other way.

An additional argument to the same effect may be drawn from the fact that many of these fevers are peculiar to man. This seems to be especially the case with the fever before us.

If the poison from which intestinal fever springs were capable of being bred elsewhere than in the human body, it would surely be in the bodies of animals which are made of flesh and blood like ourselves, and from whose substance we draw sustenance for our own. And yet it appears to be certain that this is not the case. In the most virulent outbreaks of intestinal fever, there is no evidence that even the domestic animals which gather round the fever-stricken dwelling ever take the disease. At Chaffcombe, while nearly all the human inmates of the infected homestead were laid low by the poison, the dogs and cats which belonged to the house, and the poultry, pigs, horses, and cattle which thronged the yard, continued to enjoy perfect health. And yet the pond from which the latter drank was being continually polluted by a drain which received the whole bulk of the intestinal discharges from the fever-patients.* I have observed the same striking contrast in other instances without number; and I may add, that the whole course

* Ur. Barker, of Bedford, fed a pig for three months with the discharges from intestinal fever, and found that the health of the animal in no wise suffered from this strange addition to its diet. The inference which the fact might, at first sight, seem to suggestthat these discharges are not infectious, is, I need scarcely say, quite unwarranted by it. The true inference to draw from it is, that pigs are not men. of observation bears out the conclusion to which this contrast so distinctly points. $\dagger$

But if the fever-poison cannot find the elements of its growth even in the arimals which are nearest to man-in the material conditions, that is to say, which of all others most nearly resemble those of its known mode of development-what likelihood is there of its being the offspring of conditions so radically different from these as those which are presented by common dead matter? If it cannot breed in the bodies of the cat, the dog, the pig, the horse, or the cow, how can it be conceived to breed in every ditch or dungheap?

The force of this argument is immeasurably added to when we further consider that, even in the body of man himself, the reproduction of the fererpoison requires conditions of its own.

[To lie continued.]

\section{EXTRACTS FRON A. 3) \\ TO A COUISE OF}

\section{LECTURES \\ ON CLINICAL MEDICINE.}

DELIVERED AT

THE LEEDS INFIRMARY, OCT. 2ND, 1861.

LY

J. D. HEATON, M.D.Lond., M.R.C.P.L.,

PHYSICIAN TO THE INFIRMARY; AND LECTURER ON PRACTICE OF MEDICINE AT THE LEEDS SCHOOL OF MEDICINE.

[Dr. Heaton commenced by referring to the substitution of a course of lectures on clinical medicine for one of the systematic courses of Principles and Practice of Medicine, and pointed out the differences between the two modes of instruction, the systematic being one of generalisation, and the clinical one of individualisation of diseases. Both were necessary, to illustrate and enforce each other.]

The systematic lecturer is obliged thus to generalise each disease of which he treats-to present to you the abstract idea of such disease. But these ideas have no actual existence; in the words of Locke, they are "the invention and creature of the understanding, set up as the representatives of many particular things". On the other hand, in our clinical lectures, and in practice, each case must be individualised, and considered in all its special peculiarities and relations. Even in the different branches of natural history, individual varieties of plant or animal do frequently occur which very imperfectly correspond with our specific descriptions. But in nosology-the natural history of disease-the differences of individual cases of the same species, between each other, and from their abstract descriptions, are incomparably greater; this being the result of the operation of the various disturbing causes to some of which I before alluded. And these differences may not merely obscure our diagnosis, but materially modify the nature of the treatment indicated. To take the example of pneumo. nia: were we in every case in which the physical sign of crepitation is detected in the lungs to prescribe bleeding, calomel, and tartar emetic, as being the authorised

If anything were wanting to add force to this, it would be the fact that animals, on their part, are infested by a whole brood of contagious poisons, specific in kind, each separate from the other, and all (with one or two exceptions) incapable, apparently, of multiplying in the human body. It seems to be quite established, for instance, that eattle are subject to a variety of maliguant and contagious fevers-many of them of typhoid type-from which man is altogether exempt. 